\title{
Tissue factor pathway inhibitor expression by human pleural mesothelial and mesothelioma cells
}

\author{
M.S. Bajaj*, U. Pendurthi**, K. Koenig**, S. Pueblitz**, S. Idell**
}

Tissue factor pathway inhibitor expression by human pleural mesothelial and mesothelioma cells. M.S. Bajaj, U. Pendurthi, K. Koenig, S. Pueblitz, S. Idell. (C)ERS Journals Ltd 2000.

ABSTRACT: The mesothelial lining of the pleura and malignant mesothelioma promote fibrin deposition in pleural injury or neoplasia via expression of tissue factor (TF). It was hypothesized that these cells might also regulate intrapleural coagulation by elaborating TF pathway inhibitor (TFPI).

TFPI activity and antigen in pleural fluids were assayed from patients with congestive heart failure (CHF), pneumonia, empyema, metastatic pleural cancer and malignant mesothelioma. The authors also assessed expression of TF and TFPI messenger ribonucleic acid (mRNA) as well as TFPI activity and antigen by human pleural mesothelial cells, malignant mesothelioma cells (MS-1 cell line) and human lung fibroblasts. Immunohistochemical analyses of normal, fibrotic, and neoplastic pleura were performed to determine whether TFPI antigen was expressed in vivo.

The study revealed that TFPI was present in transudates from patients with CHF and exudative pleural effusions from patients with pneumonia, empyema or pleural carcinoma. TFPI mRNA, activity and antigen were expressed by pleural mesothelial cells, MS-1 cells and lung fibroblasts. Cytokines and serum stimulated a significant early increase in TF mRNA levels with minimal enhancement of TFPI mRNA, activity and antigen levels. TFPI antigen was found in normal, fibrotic and neoplastic pleural tissues.

The current observations indicate that tissue factor pathway inhibitor is locally expressed in pleural disease, but that it does not prevent the development of a prothrombotic environment favouring local fibrin deposition in pleural inflammation or cancer.

Eur Respir J 2000; 15: 1069-1078.

Extravascular fibrin deposition is an important feature of a variety of inflammatory diseases of the pleura and of malignant pleural mesothelioma. Pleural fibrin deposition leads to loculation and formation of limiting membranes over the pleura, and is associated with fibrosis, scarring, trapped lung and restriction of lung function. The mesothelial lining of the pleura has been shown to play a central role in the deposition of fibrin on pleural surfaces [1, 2]. Intrapleural fibrin formation is initiated by elaboration of tissue factor (TF)-related procoagulant activity at the mesothelial cell surface [1]. The dissolution of fibrin takes place via expression of both tissue plasminogen activator and urokinase plasminogen activator, also expressed by the mesothelial cells [1]. Additionally, in mesothelioma, the tumour cells express procoagulants and fibrinolysins and extravascular fibrin deposition occurring within the tumour stroma may promote tumour extension [3]. Similarly, human lung fibroblasts (HLF) are also known to express TF-related procoagulant activity as well as fibrinolytic activity [4]. Thus, human pleural mesothelial cells (HPMC) and malignant mesothelioma cells as well as HLF may autoregulate the local turnover of fibrin in the pleural space by expression of procoagulants and fibrinolysins. In pleural inflammation or neoplasia, which bears a similarity to an inflammatory state $[5,6]$, upregulation
*Dept of Internal Medicine, Saint Louis University School of Medicine, St. Louis, MO, USA. **Dept of Medical Specialties, The University of Texas Health Sciences Center, Tyler, TX, USA.

Correspondence: M.S. Bajaj, St. Louis University Health Sciences Center, Division of Pulmonology, 3635 Vista Ave., P.O. Box 15250, St. Louis, MO 631100250, USA. Fax: 13145778859

\section{Keywords: Anticoagulant} mesothelial cells pleura

tissue factor pathway inhibitor

Received: December 161997

Accepted after revision December 51999

Supported by NIH Clinical Invesitgator Development Award HL03237 and RO1 HL45018. of procoagulant activity and a decrease in fibrinolytic activity by these cells due to increased expression of plasminogen activator inhibitor- 1 and -2 concurrently, favours fibrin formation $[1,3]$. In both circumstances, it is likely that an imbalance favouring mesothelial cell procoagulant versus fibrinolytic activity is mediated by selected cytokines, including transforming growth factor (TGF)- $\beta$ and tumour necrosis factor (TNF)- $\alpha$ [1].

TF pathway inhibitor (TFPI) plays a dominant role in regulating TF-induced coagulation [7-9]. It is primarily synthesized by the microvascular endothelium under physiological conditions [10] and in small amounts by megakaryocytes and macrophages [11]. It has a molecular weight of $\sim 42,000 \mathrm{Da}$ with three Kunitz type inhibitor domains. Immunodepletion of TFPI sensitizes rabbits to endotoxin [12] and TF-induced [13] disseminated intravascular coagulation, suggesting an important role for TFPI in the pathophysiology of coagulation. Abnormal TF-induced coagulation is an essential feature of many pathological conditions including pleural fibrin deposition [1], sepsis, malignancy, acute respiratory distress syndrome, atherosclerotic plaques and glomerulonephritis [14]. Endothelium (intravascular), monocytes/macrophages (intra- and extravascular) and fibroblasts (extravascular) are the primary cells implicated in causing abnormal 
coagulation in these conditions $[14,15]$. These cell types appear to regulate both intravascular and extravascular clotting by expressing TFPI under pathological conditions. Specifically, microvascular endothelial cells, which express TFPI under physiological conditions, upregulate TFPI expression under inflammatory conditions [16]. Additionally, adherent monocytes [17], serum-stimulated fibroblasts [18], vascular smooth muscle cells [19, 20] and cardiac myocytes [19] are known to express TF as well as TFPI in vitro. Of note, in all of the above cell types, TF expression appears to precede TFPI expression, suggesting that an initial imbalance between procoagulant and anticoagulant activities in the cellular microenvironment favours local fibrin formation.

Besides regulating coagulation in their microenvironment via fibrinolysis, another possible mechanism by which mesothelial and mesothelioma cells, as well as fibroblasts, may regulate local TF procoagulant activity could involve expression of TFPI. Both mesothelioma cells [3] and rabbit pleural mesothelial cells [21] are known to elaborate TFPI protein. It was thus inferred that TFPI may be expressed by the mesothelial cells in situ in humans. The authors therefore sought to determine whether TFPI was expressed in pleural effusions in a spectrum of common pleural diseases. The authors also sought to determine whether HPMC and HLF, as well as malignant mesothelioma cells, could contribute to local, intrapleural, elaboration of TFPI and determine the effects of pro-inflammatory mediators on the expression of this anticoagulant.

\section{Methods}

\section{Patients}

Pleural fluid was obtained from 59 patients undergoing thoracentesis for different clinical conditions at the University of Texas Health Sciences Center at Tyler, TX, USA. All human study protocols were approved by the Human Subjects Institutional Review Committee of the University of Texas Health Sciences Center. These patients had the following underlying disorders: congestive heart failure $(\mathrm{CHF} ; \mathrm{n}=14)$, pneumonia $(\mathrm{n}=8)$, empyema $(\mathrm{n}=9)$, metastatic pleural (lung, breast, prostate or melanoma) cancer $(n=26)$ and malignant mesothelioma $(n=2)$. Diagnostic criteria were as previously described [22]. Pleural fluids from patients with CHF were transudative, and those from patients with pneumonia, empyema or cancer were exudative, as previously described $[22,23]$.

\section{Cell cultures}

Media, serum and supplements for media were obtained from Gibco BRL (Gaithersburg, MD, USA). All primary cells and cell lines used were cultured in Roswell Park Memorial Institute medium supplemented with 10\% heat-inactivated foetal calf serum, antibiotics and 1\% Lglutamine. HPMC were harvested from pleural effusions aspirated for clinical indications [1]. HLF were obtained from explants of lung tissue. These cells were then characterized as previously described [1] and used at passage 4-5. The simian vacuolating virus-40 transformed mesothelial cell line MeT5A was obtained from B. Gerwin of the National Institutes of Health, Bethesda, MD, USA. A mesothelioma cell line (MS-1), was obtained from H.S. Hsu, University of Arkansas, Little Rock, AR, USA and has been previously characterized [3]. One to two days after the cells reached confluence, they were serum-starved overnight in media free of serum and stimulated with various stimuli as follows: serum $(10 \%$ volume $(\mathrm{v}) / \mathrm{v})$; lipopolysaccharide (LPS; $\left.1 \mu \mathrm{g} \cdot \mathrm{mL}^{-1}\right)$; TGF; $\left(10 \mathrm{ng} \cdot \mathrm{mL}^{-1}\right)$; TNF (10 ng. $\left.\mathrm{mL}^{-1}\right)$; beta fibroblast growth factor (bFGF; $10 \mathrm{ng} \cdot \mathrm{mL}^{-1}$ plus $15 \mathrm{U} \cdot \mathrm{mL}^{-1}$ heparin); phorbol myristate acetate (PMA; $\left.10 \mathrm{ng} \cdot \mathrm{mL}^{-1}\right)$; interleukin (IL)-1 (10 $\left.\mathrm{ng} \cdot \mathrm{mL}^{-1}\right)$; and thrombin $\left(4 \mathrm{U} \cdot \mathrm{mL}^{-1}\right)$. Cells were harvested after $2 \mathrm{~h}$ and $8 \mathrm{~h}$ of stimulation with these agents. LPS contamination of media and stimulating agents was ruled out by the E-Toxate assay kit (Sigma Chemical Co., St Louis, MO, USA).

Northern blotting determinations of steady-state messenger ribonucleic acid

Total cellular ribonucleic acid (RNA) was isolated by the method of CHOMCZYNSKI and SACCHI [24] using TRI reagent (Molecular Research Center, Inc., Cincinnati, OH, USA). Ten micrograms of total RNA were electrophoresed on $1 \%$ agarose containing $2.2 \mathrm{M}$ formaldehyde, transferred to nitrocellulose and hybridized with ${ }^{32} \mathrm{P}$-labelled TF and TFPI complementary deoxyribonucleic acid (cDNA) probes. The human TF cDNA probe was a 900-base pair fragment cloned into Eco RI sites in Bluescript vector. The human TFPI cDNA probe was a $1.4-\mathrm{kb}$ fragment cloned into Eco RI sites in Bluescript vector. The same filters were stripped and reprobed with different cDNA probes. Before rehybridization, removal of the previous probe was confirmed by autoradiography. The hybridized filters were exposed to phosphor screens and read using a phosphor imager (Molecular Dynamics, Sunnyville, CA, USA). The data for both TF and TFPI messenger (m)RNA was quantitated by densitometry using ImageQuant NT software (Molecular Dynamics) and corrected for loading differences using human 28-S RNA, stained by ethidium bromide, as an internal control.

Processing of conditioned media and pleural fluids and assay for tissue factor pathway inhibitor activity

Conditioned media from HPMC, MeT5A, MS-1 and $\mathrm{HLF}$ cells in culture as well as pleural fluids were centrifuged at $80,000 \times g$ for $30 \mathrm{~min}$ at $4^{\circ} \mathrm{C}$ to remove TF membrane particles, assayed to confirm removal of TF and concentrated 10-fold, using Amicon YM-10 filters (Amicon, Danvers, MA, USA). This technique has been shown to be adequate for TF removal [10, 16, 19, 25-27]. Concentrated conditioned media and pleural fluids were assayed for TFPI activity by a modification of a functional assay that measures the release of factor IX activation peptide. The assay is based upon the ability of TFPI to inhibit VIIa/TF-catalysed activation of sialyl ${ }^{3} \mathrm{H}-\mathrm{IX}$ in the presence of factor Xa but not in its absence. The assay uses a standard curve constructed from human normal pooled plasma from 20 donors arbitrarily assigned to contain $1,000 \mathrm{mU} \cdot \mathrm{mL}^{-1}$ TFPI activity. Thus, a test sample containing $100 \mathrm{mU} \cdot \mathrm{mL}^{-1}$ of TFPI activity is equal to $10 \%$ of plasma levels of TFPI. The details of the assay have been described previously [26]. The assay has been found to be reliable in measuring TFPI levels in conditioned media of 
a variety of cells $[10,16,19]$, in plasma [26, 27] and in body fluids [26]. Since no other known factor inhibits the VIIa/TF-catalysed activation of sialyl ${ }^{3} \mathrm{H}$-IX in the presence of factor Xa, this assay becomes highly specific for TFPI $[26,27]$. Moreover, the functional assay for TFPI activity has been shown to highly correlate with TFPI antigen [28].

Enzyme-linked immunosorbent assay for detection of tissue factor pathway inhibitor antigen in pleural fluids and conditioned media

Pleural fluids and conditioned media were processed as described above. TFPI antigen determination was performed using the commercially available Imubind total TFPI enzyme-linked immunosorbent assay (ELISA) kit (American Diagnostica, Inc., Greenwich, CT, USA). This assay recognizes full length native and recombinant human TFPI complexed with lipoproteins, as well as truncated forms of human TFPI. No significant cross-reactivity or interference with other coagulation factors has been observed. The lower limit of detection is $0.36 \mathrm{ng} \cdot \mathrm{mL}^{-1}$. Using this kit, undiluted normal plasma from healthy volunteers is calculated to have a mean value of $90 \mathrm{ng}$ TFPI $\cdot \mathrm{mL}^{-1}$ plasma with a range of $75-120 \mathrm{ng}$ TFPI $\cdot \mathrm{mL}^{-1}$ plasma. Aliquots $(100 \mu \mathrm{L})$ of different dilutions of pleural fluid or conditioned media were used and the ELISA was performed according to the manufacturer's instructions. Results are expressed as ng TFPI. $\mathrm{mL}^{-1}$ for pleural fluids and $\mathrm{ng}$ TFPI $10^{6}$ cells $^{-1}$ for conditioned media.

\section{Immunohistochemical analysis of pleural tissues}

Human tissues were obtained from surgical specimens following decortication or lung resection. Surgical specimens included normal pleura, fibrotic pleura and pleura invaded by adenocarcinoma of the lung. Immunohistochemical analysis of pleural tissue was carried out as previously described [3]. The formalin-fixed and paraffinembedded tissue specimens were deparaffinized with Clear-Rite 3 (Richard-Allyn, Richland, MI, USA), rehydrated and incubated with mouse antihuman TFPI domain 1 monoclonal antibody (American Diagnostica, Inc.) at $1 \mu \mathrm{g} \cdot \mathrm{mL}^{-1}$, overnight at $4^{\circ} \mathrm{C}$. Nonimmune mouse immunoglobulin (Ig)G (Sigma Chemical Co.) was used as a negative control. The Supersensitive Multilink System (Biogenex, San Ramos, CA, USA) was used to detect immunoreactivity as follows. Biotinylated anti-Ig at 1:20 dilution was used as a secondary antibody. The reaction was developed using alkaline phosphatase-conjugated streptavidin and naphthol phosphate with fast red as the chromogen.

\section{Statistics}

Values were expressed as mean \pm SEM. The distribution of TFPI levels in pleural fluids was normal. Hence the analysis of variance test followed by the Student-NewmanKeuls test was used to determine significant differences between means of different groups, using the Instat program (Graph Pad Software, San Diego, CA, USA). The
Pearson's correlation test was used for determining correlations between pleural fluid protein and TFPI levels (Graph Pad Software). A p-value of $<0.05$ was considered significant.

\section{Results}

Tissue factor pathway inhibitor activity and antigen in pleural fluids

TFPI activity in pleural fluid samples was not affected by extended storage at $-70^{\circ} \mathrm{C}$ for $1 \mathrm{yr}$, and upon repeated freezing and thawing (three times). The mean TFPI activity levels $\left(\mathrm{mU} \cdot \mathrm{mL}^{-1}\right)$ in pleural fluid samples from patients with CHF, pneumonia, empyema and metastatic pleural cancer are presented in figure 1. Mean pleural fluid TFPI levels were not significantly different in any group when compared with all other groups ( $>>0.05)$. Data for mesothelioma are not depicted in figure 1 as only two patients were studied. The median value and range (in parentheses) of pleural fluid TFPI levels $\left(\mathrm{mU} \cdot \mathrm{mL}^{-1}\right)$ were as follows: $\mathrm{CHF}=331(206-1,000)$, pneumonia $=450(200-$ $1,300)$, empyema $=300(50-700)$, metastatic pleural cancer $=475(275-1,390)$, and mesothelioma $=150(100-200)$.

No correlation was found between pleural fluid protein and TFPI levels $(r=0.22, p>0.05$; fig. 2$)$. The pleural fluid TFPI levels were not compared to the clinical outcome such as loculation in empyema, given the relatively small numbers of pleural fluids examined.

The authors next sought to demonstrate TFPI antigen in pleural fluids. By ELISA, the authors were able to demonstrate TFPI immunoreactive protein in pleural fluid samples from all groups. The mean values of TFPI antigen $\left(\mathrm{ng} \cdot \mathrm{mL}^{-1}\right)$ in pleural fluids were as follows: $\mathrm{CHF}=49.6$, pneumonia $=60.8$, empyema $=37.5$, metastatic pleural cancer $=58.7$, and mesothelioma $=17.5$. The mean pleural fluid TFPI antigen levels did not differ significantly between any two groups $(\mathrm{p}>0.05)$.

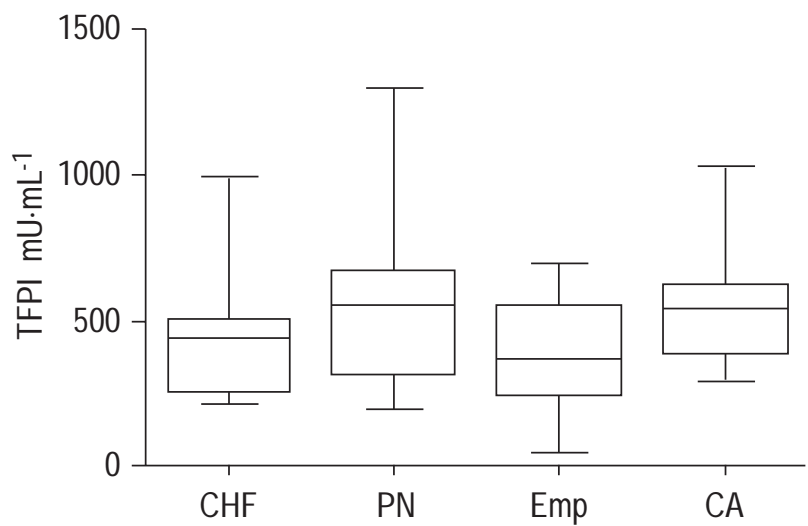

Fig. 1. - Tissue factor pathway inhibitor (TFPI) activity levels in pleural fluids. Box plots depicting TFPI levels in pleural fluids from 14 patients with congestive heart failure (CHF), eight patients with pneumonia $(\mathrm{PN})$, nine patients with empyema (Emp) and 26 patients with metastatic pleural cancer (CA). Each box indicates the range between 25 th and 75 th percentiles of data; the horizontal line inside the box marks the value of the mean. Capped bars indicate the 5th and the 95th percentile points. For each group, $\mathrm{p}>0.05$ when compared with all other groups. 


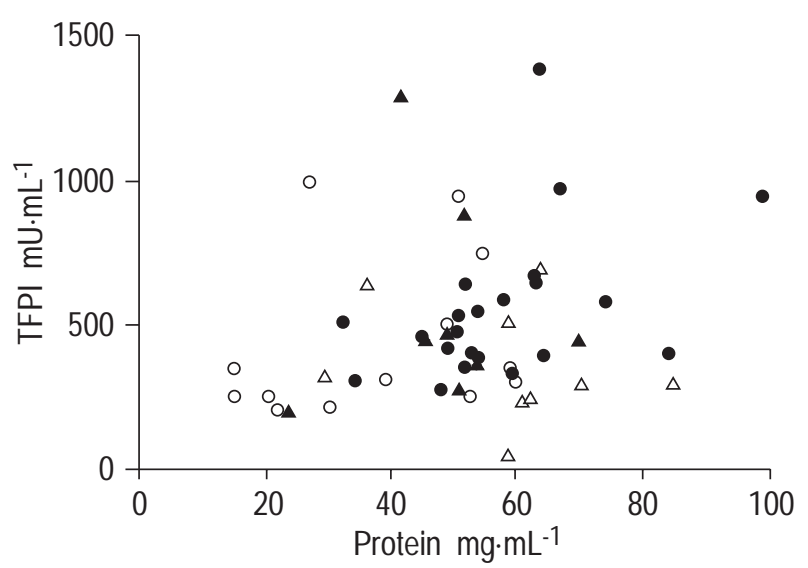

Fig. 2. - Correlation between pleural fluid tissue factor pathway inhibitor (TFPI) and protein levels in pleural fluids from patients with congestive heart failure $(\bigcirc)$, pneumonia $(\boldsymbol{\Delta})$, empyema $(\triangle)$ and metastatic pleural cancer $(\mathbf{O})$. Numbers for all groups are as in figure 1 . Each data point reflects the mean of 2-4 determinations of TFPI levels in a pleural fluid sample. $r=0.22, \mathrm{p}>0.05$.

Tissue factor and tissue factor pathway inhibitor expression by human pleural mesothelial cells and MeT5A cells

Serum-starved HPMC express moderate amounts of TFPI mRNA at baseline (fig. 3a). These cells contain two previously described TFPI mRNA species of $4.0 \mathrm{~kb}$ and $1.4 \mathrm{~kb}[10]$. At $8 \mathrm{~h}$ there was little induction of TFPI mRNA by any of the selected agents $(\mathrm{bFGF}=1.3$-fold, $\mathrm{PMA}=1.4$-fold), as illustrated in figure $3 \mathrm{a}$ and $\mathrm{b}$.

The authors next sought to determine whether MeT5A cells expressed TF and TFPI mRNA (fig. 3c). The densitometry data for TFPI mRNA are shown in figure $3 \mathrm{~d}$. Since the fold increase in TF mRNA was large and quite apparent on Northern blotting, densitometry data for TF are not provided. MeT5A cells express minimal amounts of TF mRNA under conditions of starvation (control). A several-fold increase in TF mRNA levels was observed upon induction with the following stimuli at $2 \mathrm{~h}$ : serum= three-fold; TGF- $\beta=$ two-fold; TNF- $\alpha=2.8$-fold; $b F G F=$ 6.1 -fold; and $\mathrm{PMA}=12.8$-fold. Interestingly, no significant change in TF mRNA levels was induced by LPS. TF mRNA levels returned to baseline upon continued stimulation with all of the above pro-inflammatory agents at $8 \mathrm{~h}$. In contrast, these cells express significant amounts of TFPI mRNA at baseline under conditions of starvation. Both $4.0 \mathrm{~kb}$ and $1.4 \mathrm{~kb}$ species of TFPI mRNA were identified. There was no increase in TFPI mRNA at $2 \mathrm{~h}$ upon stimulation with any of the selected agents. However, upon continued stimulation for $8 \mathrm{~h}$ with bFGF and PMA, a marginal ( 1.4-fold) increase in TFPI mRNA levels in these cells was observed.

The ability of HPMC and MeT5A cells to express functional TFPI activity in conditioned media was also determined. Small-to-moderate, but reliably detectable, amounts of TFPI activity were found in conditioned media from both cell types. The TFPI activity $\left(\mathrm{mU} \cdot 10^{6}\right.$ cells $\left.^{-1}\right)$ in conditioned media of HPMC at $8 \mathrm{~h}$ was as follows: serumstarved $=2$; serum-stimulated $=65 ;$ LPS $=37 ;$ TGF $-\beta=130$; $\mathrm{TNF}-\alpha=2 ; \mathrm{bFGF}=7$; and PMA=35. In MeT5A cells, the TFPI activity $\left(\mathrm{mU} \cdot 10^{6}\right.$ cells $\left.^{-1}\right)$ in conditioned media at $8 \mathrm{~h}$ was as follows: serum-starved $=41$; serum-stimulated $=166$; $\mathrm{LPS}=25$; TGF- $\beta=41$; TNF- $\alpha=140 ; \mathrm{bFGF}=30$; and $\mathrm{PMA}=$
77. Cell lysates were not analysed for TFPI activity as the presence of TF in the lysates interferes with the TFPI activity assay.

TFPI antigen was found in detectable amounts in conditioned media from HPMC and MeT5A cells. The TFPI antigen (ng. $10^{6}$ cells $\left.^{-1}\right)$ in conditioned media from HPMC at $8 \mathrm{~h}$ were as follows: serum-starved=not detectable; serum-stimulated $=7.2$; LPS $=4.0$; TGF- $\beta=15.3$; TNF$\alpha=$ not detectable; $b F G F=1.2$; and PMA $=3.5$. The TFPI antigen (ng. $10^{6}$ cells $^{-1}$ ) in conditioned media from MeT5A cells at $8 \mathrm{~h}$ were as follows: serum-starved $=4.6$; serum-stimulated=15.6; LPS=3.3; TGF- $\beta=4.1$, TNF- $\alpha=16.7$; $\mathrm{bFGF}=3.0$; and $\mathrm{PMA}=8.4$. Thus, in general, a correlation was found between TFPI activity and antigen levels as has been previously reported [28].

Tissue factor and tissue factor pathway inhibitor expression by MS-1 mesothelioma cells

Figure 4 depicts TF and TFPI mRNA expression by MS-1 cells. These cells expressed small amounts of TF mRNA at baseline after serum-starvation (control). A several-fold increase in TF mRNA levels was observed upon induction with the following stimuli at $2 \mathrm{~h}$ : serum= five-fold; TNF- $\alpha=$ two-fold; and PMA=four-fold (fig. 4). Except for stimulation with PMA when mRNA levels further increased to seven-fold at $8 \mathrm{~h}$, TF mRNA levels returned to baseline upon continued stimulation with other agents. LPS, TGF- $\beta$ and bFGF had no stimulatory effect at $2 \mathrm{~h}$ or $8 \mathrm{~h}$. Additionally, MS-1 cells expressed detectable amounts of TFPI mRNA at baseline under serum-starved conditions. Like HPMC and MeT5A, these cells also contain the two known TFPI mRNA species, $4.0 \mathrm{~kb}$ and $1.4 \mathrm{~kb}$ (fig. 4). There was no increase in TFPI mRNA levels at $2 \mathrm{~h}$ upon stimulation with any of the selected agents (fig. 4). Upon continued stimulation for 8 $\mathrm{h}$, a 1.8- fold increase with serum and a 1.6-fold increase with PMA compared with control (serum-starved state) was observed in TFPI mRNA levels.

The TFPI activity ( $\mathrm{mU} \cdot 10^{6}$ cells $^{-1}$ ) in the conditioned media of MS- 1 cells at $8 \mathrm{~h}$ was as follows: serum-starved $=$ 2 ; serum-stimulated $=6$; LPS $=2 ;$ TGF- $\beta=1 ;$ TNF- $\alpha=11$; $\mathrm{bFGF}=8$; and PMA $=6$. Thus, TFPI activity levels did not increase significantly from baseline upon stimulation.

As in the case of TFPI activity, minimal amounts of TFPI antigen were detected in conditioned media from serum-starved MS-1 cells, which did not increase significantly with any of the stimulating agents. The TFPI antigen levels (ng. $10^{6}$ cells $^{-1}$ ) in conditioned media from MS-1 cells at $8 \mathrm{~h}$ were as follows: serum-starved=not detectable; serum-stimulated $=0.5$; LPS $=$ not detectable; $T G F=$ not detectable; $\mathrm{TNF}=1.2 ; \mathrm{bFGF}=1.1$; and $\mathrm{PMA}=0.7$.

Tissue factor and tissue factor pathway inhibitor expression by human lung fibroblasts

Finally, the expression of TF and TFPI by HLF (fig. 5) was assessed. Serum-starved (control) HLF expressed minimal amounts of TF mRNA. An equal degree of increase, approximately six-fold, was seen at $2 \mathrm{~h}$ upon stimulation with serum, IL-1 and PMA. A modest increase, approximately two-fold, was observed with TGF- $\beta$ and thrombin at $2 \mathrm{~h}$ and no induction was seen with LPS. Upon continued stimulation at $8 \mathrm{~h}$, TF mRNA levels returned to baseline except for cells treated with serum and 

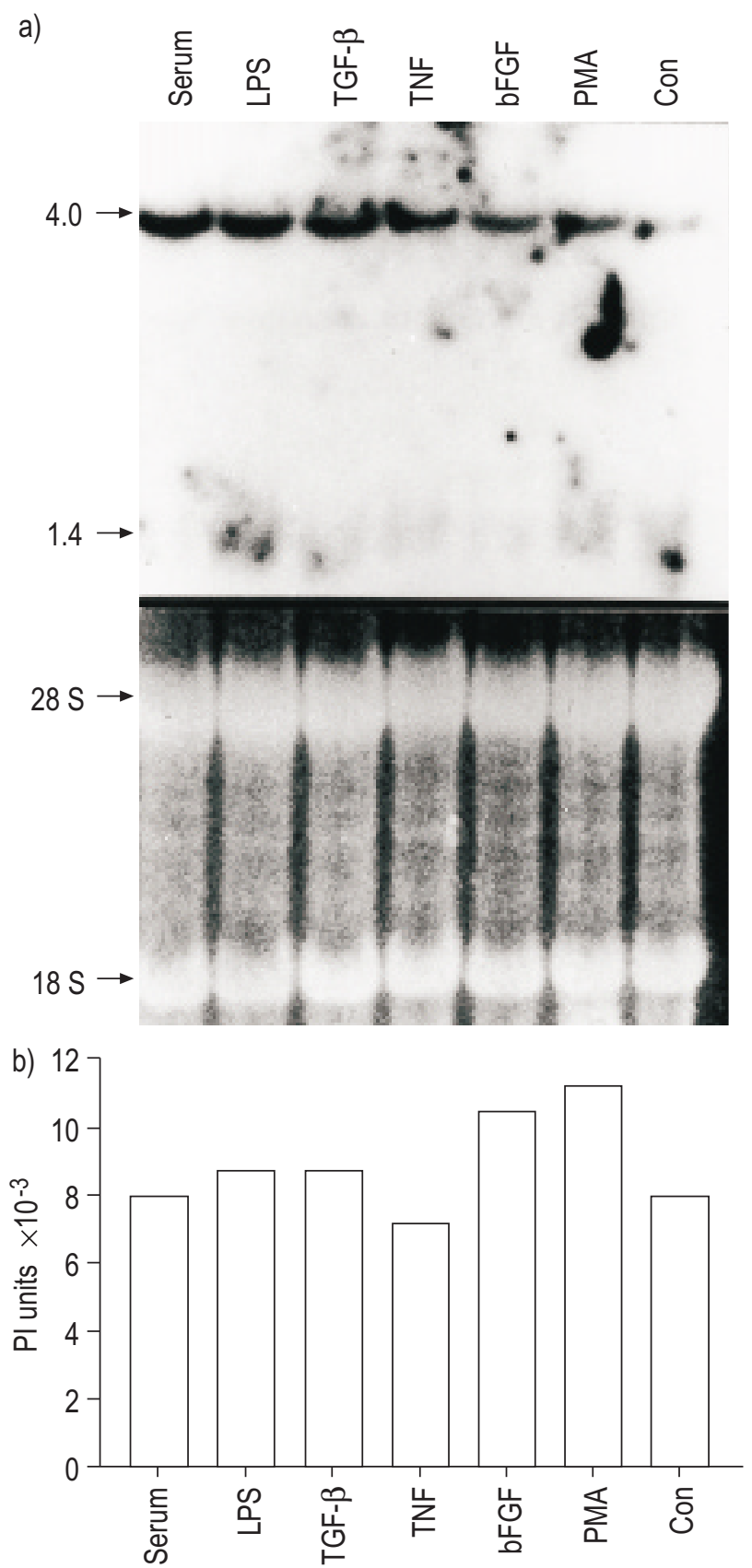

Fig. 3. - Northern blot analysis of tissue factor pathway inhibitor (TFPI) messenger ribonucleic acid (mRNA) in cultured stimulated human pleural mesothelial cells (HPMC). a) Northern blot, and b) bar graph of densitometry showing combined 4.0 - and $1.4-\mathrm{kb}$ bands of TFPI mRNA. Tissue factor (TF) and TFPI mRNA in MeT5A cells. c) Northern blot, and d) bar graph of densitometry showing combined $4.0-$ and $1.4-\mathrm{kb}$ bands of TFPI mRNA, ( $\square: 2 \mathrm{~h} ; \mathbb{\mathbb { Q }}: 8 \mathrm{~h})$. Cells were serum-starved overnight followed by treatment with the indicated stimuli (see Methods section) and analysed at $8 \mathrm{~h}$ (HPMC) and $2 \mathrm{~h}$ and $8 \mathrm{~h}$ (MeT5A). Ten micrograms of total ribonucleic acid (RNA) was loaded in each lane. A single species of TF mRNA was detected. Both $4.0-\mathrm{kb}$ and $1.4-\mathrm{kb}$ species of TFPI mRNA were detected. RNA (28 S) stained with ethidium bromide was used as an internal control. Representative findings from three sets of experiments are shown. LPS: lipopolysaccharide; TGF- $\beta$ : transforming growth factor- $\beta$; TNF: tumour necrosis factor; bFGF: beta fibroblast growth factor; PMA: phorbol myristate acetate; TF: tissue factor; TFPI: tissue factor pathway inhibitor; Con: unstimulated serumstarved control; PI units: phosphor imager units. c)
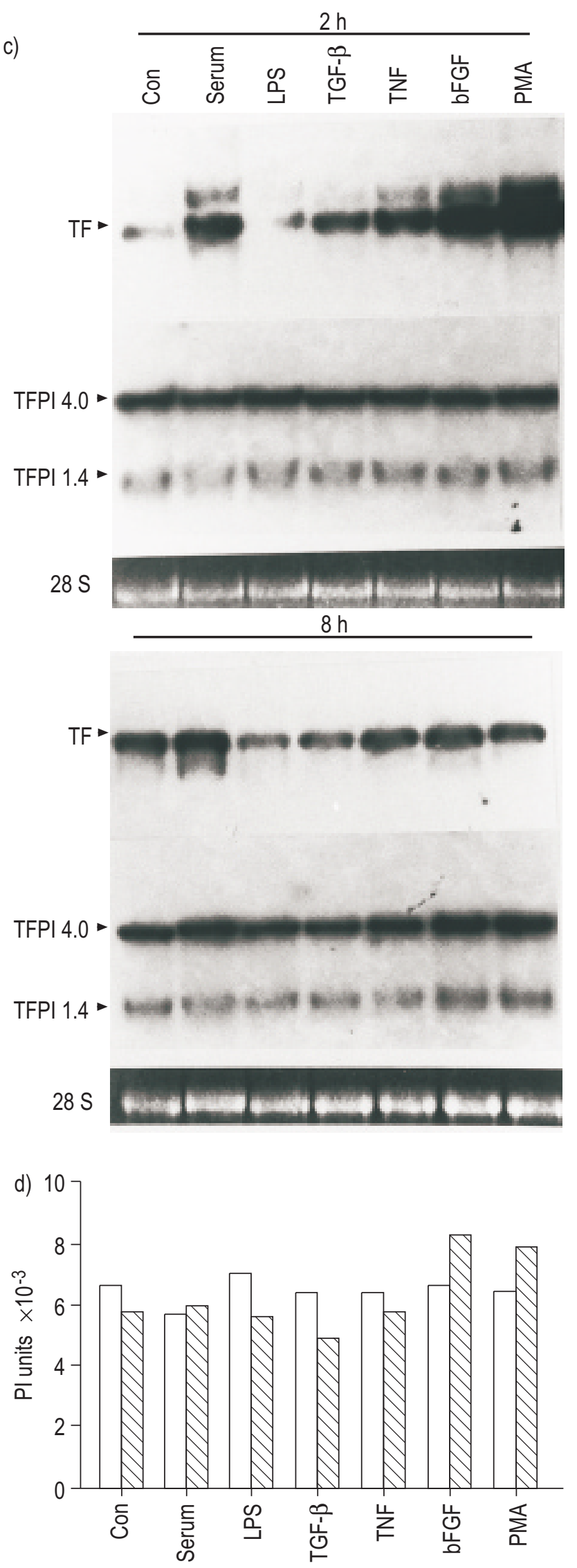
a)

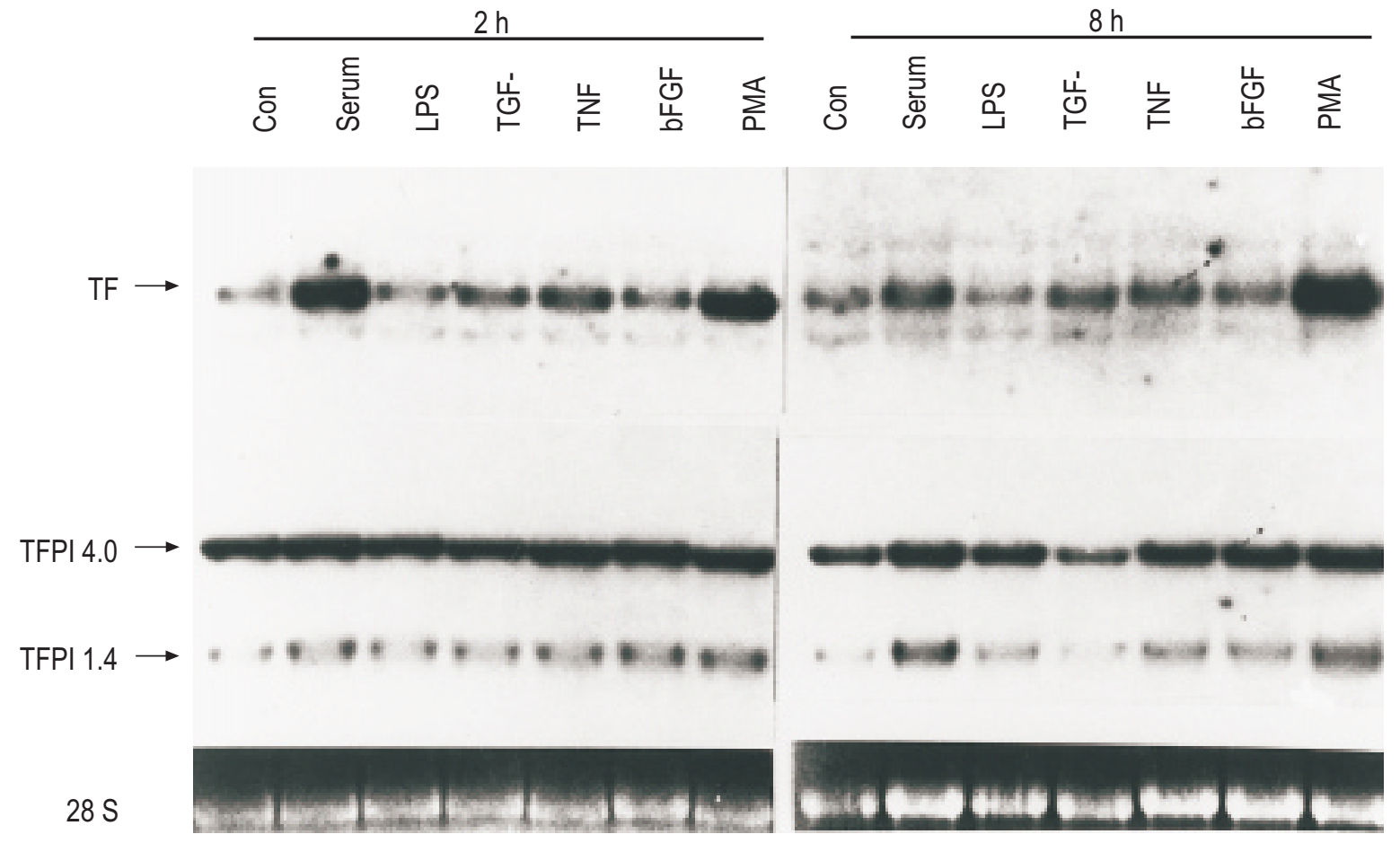

b)

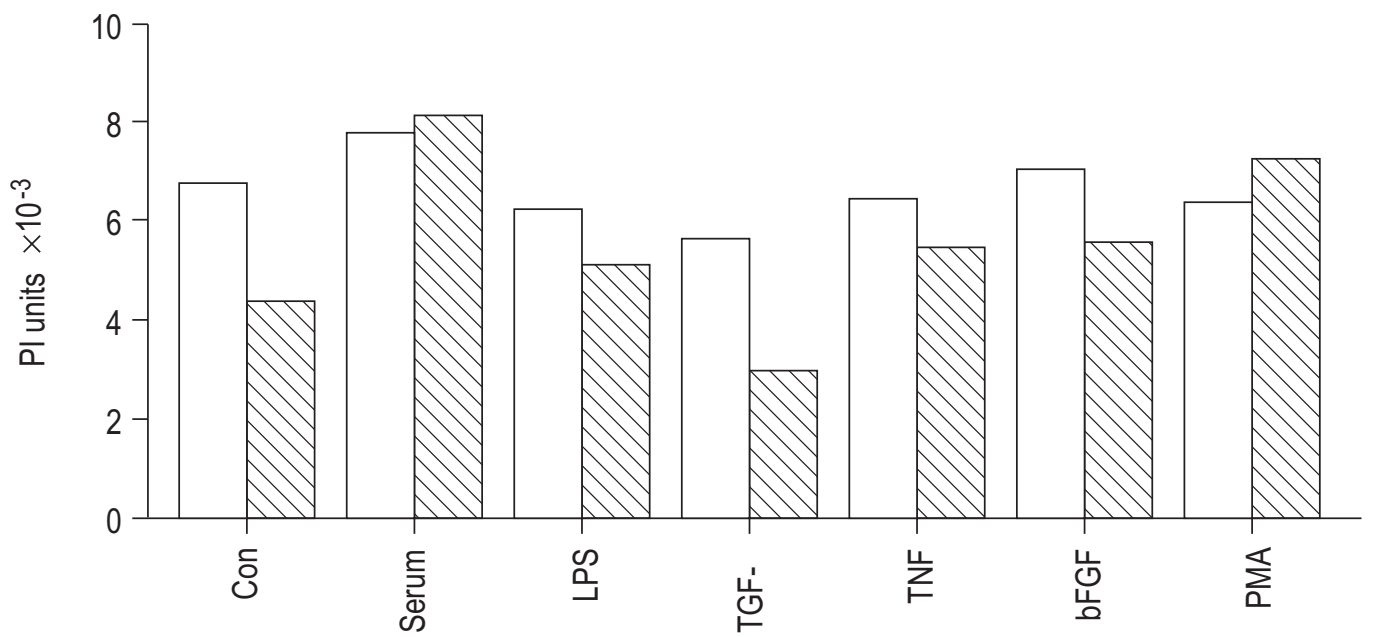

Fig. 4. - a) Northern blot analysis of tissue factor (TF) and tissue factor pathway inhibitor (TFPI) messenger ribonucleic acid (mRNA) in cultured MS-1 mesothelial cells. b) Bar graph of densitometry showing combined 4.0- and 1.4-kb bands of TFPI mRNA ( $\square: 2$ h; $\mathbb{\mathbb { N }}: 8 \mathrm{~h}$ ). Serum-starved cells were treated with the indicated stimuli. Cells were harvested and analysed at $2 \mathrm{~h}$ and $8 \mathrm{~h}$. Ten micrograms of total ribonucleic acid (RNA) was loaded in each lane. Both 4.0-kb and 1.4-kb species of TFPI mRNA were detected. RNA $(28 \mathrm{~S})$ stained with ethidium bromide was used as an internal control. Representative findings from three sets of experiments are shown. Con: unstimulated serum-starved control; LPS: lipopolysaccharide; TGF- $\beta$ : transforming growth factor- $\beta$; TNF: tumour necrosis factor; bFGF: beta fibroblast growth factor; PMA: phorbol myristate acetate; TF: tissue factor; TFPI: tissue factor pathway inhibitor; PI units: phosphor imager units.

thrombin, in which levels remained elevated at approximately two-fold (fig. 5). TFPI mRNA levels were detectable in significant amounts in the RNA harvested from HLF following serum starvation overnight (fig. 5). TFPI mRNA expression was increased only marginally at $8 \mathrm{~h}$ with serum ( 1.2-fold) and PMA ( 1.4-fold; fig. 5). None of the other stimuli had any detectable impact on TFPI mRNA levels at $2 \mathrm{~h}$ and $8 \mathrm{~h}$.

TFPI activity $\left(\mathrm{mU} \cdot 10^{6}\right.$ cell $\left.^{-1}\right)$ at $8 \mathrm{~h}$, in conditioned media of HLF was as follows: serum-starved $=16$; serum-stimulated $=62 ;$ TGF- $\beta=6 ; \mathrm{bFGF}=6 ; \mathrm{PMA}=10 ; \mathrm{LPS}=6$; and IL-1= 10 . Thus, upon serum-stimulation, significantly more in- crease in TFPI activity than in TFPI mRNA was seen when compared with baseline (serum-starved state).

The TFPI antigen levels (ng. $10^{6}$ cells $^{-1}$ ) in conditioned media at $8 \mathrm{~h}$ from HLF were as follows: serum-starved= 1.8; serum-stimulated $=7.2 ; \mathrm{TGF}=0.5 ; \mathrm{bFGF}=0.6 ; \mathrm{PMA}=$ 1.3; LPS=0.5; and IL-1 $=1.4$.

Tissue factor pathway inhibitor antigen expression in pleural tissues

Figure 6 depicts the results of immunohistochemical analysis for TFPI antigen expression by normal and 
a)
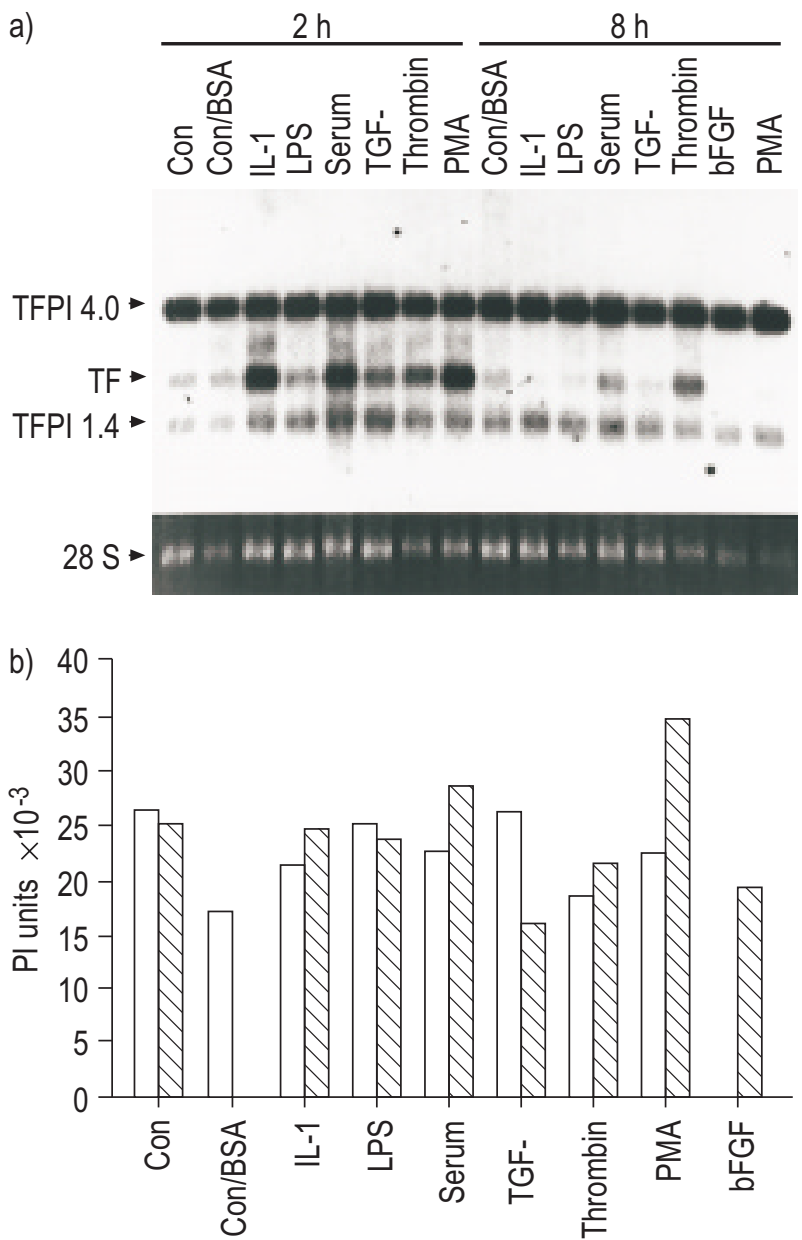

Fig. 5. - a) Northern blot analysis of tissue factor (TF) and tissue factor pathway inhibitor (TFPI) messenger ribonucleic acid (mRNA) in cultured adult human lung fibroblasts. b) Bar graph of densitometry shows combined 4.0- and 1.4-kb bands of TFPI mRNA ( $\square: 2 \mathrm{~h} ; \mathbb{\$}: 8 \mathrm{~h}$ ). Serum-starved cells treated with the indicated stimuli were harvested and analysed at $2 \mathrm{~h}$ and $8 \mathrm{~h}$. Ten micrograms of total ribonucleic acid (RNA) was loaded in each lane. Both $4.0-\mathrm{kb}$ and $1.4-\mathrm{kb}$ species of TFPI mRNA were detected. RNA (28 S) stained with ethidium bromide was used as an internal control. Representative findings from three sets of experiments are shown. Con: unstimulated serum-starved control; Con/ BSA: control with bovine serum albumin; IL-1: interleukin-1; LPS: lipopolysaccharide; TGF- $\beta$ : transforming growth factor- $\beta$; PMA: phorbol myristate acetate; TFPI: tissue factor pathway inhibitor; TF: tissue factor; bFGF: beta fibroblast growth factor; PI units: phosphor imager units.

fibrotic pleura and pleura infiltrated with adenocarcinoma of the lung. Normal visceral pleura (fig. 6a) was found to express TFPI antigen at the mesothelial cell surface. While the mesothelium clearly expressed TFPI antigen, expression by other cell types in the submesothelium was less clearly discernible. In general, the staining was not confined to the mesothelium but was found in submesothelial tissues and appeared to involve microvascular endothelium and alveolar macrophages as has been previously reported [11]. TFPI has also been previously reported to be present in fibroblasts and vascular smooth muscle cells [18-20]. It appears that the expression of TFPI in the microvascular endothelium, macrophages, fibroblasts and vascular smooth muscle cells may explain the presence of the submesothelial TFPI stain seen in figure 6a. Fibrotic pleura (fig. 6b) also expresses TFPI antigen in amounts comparable to normal pleura. Sections of pleura invaded with adenocarcinoma (fig. 6c) depict large quantities of stromal TFPI antigen in areas invaded by tumour. The preponderance of TFPI antigen in these sections appears to be extracellular but contiguous to the tumour cells. Increased amounts of TFPI antigen are also expressed by the reactive overlying visceral pleural layer. Sections stained with control primary antibody were nonreactive in all cases (data not shown).

\section{Discussion}

Pleural loculation and fibrosis are common complications of pleural inflammation with fibrin deposition. Once established, pleural adhesion may cause significant morbidity and restriction of underlying lung function. Determining how pleural mesothelial cells regulate fibrin deposition in their microenvironment could suggest strategies to limit pleural fibrin deposition and its consequences. In pleural neoplasia, including malignant mesothelioma, extravascular fibrin forms an integral part of the transitional neoplastic stroma and may therein promote the growth and extension of pleural tumours. The present study was undertaken to determine whether TFPI could influence local fibrin turnover by being expressed in the pleural space. Having shown by pleural fluid analyses that TFPI was expressed in the pleural compartment in CHF as well as in a variety of clinical scenarios associated with formation of exudative pleural effusions, the authors sought to determine whether TFPI was elaborated by mesothelial and mesothelioma cells and lung fibroblasts in vitro and in vivo. The findings indicate that these cells as well as normal, fibrotic and neoplastic pleural tissues express TFPI. Thus it appears that TFPI is expressed in the pleural compartment and may regulate local fibrin deposition.

Pleural fluids from patients with various aetiologies were found to contain readily detectable amounts of TFPI activity. The pleural fluid TFPI activity and antigen levels in $\mathrm{CHF}$ did not differ significantly from those found in pneumonia, empyema or metastatic pleural disease. In CHF, pleural fluid TFPI could, in part, derive from plasma, due to increased hydrostatic pressures. However, the pleural fluid TFPI levels did not correlate significantly with pleural fluid protein levels, raising the possibility that pleural fluid TFPI levels could also be derived from cells present in the mesothelial lining of the pleura. The presence of TFPI activity and antigen in the conditioned media of mesothelial cells supports the latter possibility. Although only small-to-moderate amounts of TFPI activity and antigen were found in the conditioned media at $8 \mathrm{~h}$, it is likely that over longer periods, significant amounts of TFPI are secreted into the conditioned media by these cells, as has been shown for fibroblasts and vascular smooth muscle cells which, at $24 \mathrm{~h}$ after serum-stimulation, contain more TFPI antigen in their conditioned media than in cell lysates [19]. Thus, it is conceivable that considerable quantities of TFPI may be released from mesothelial cells lining the pleura, into the pleural fluid, over time. Thus secretion from HPMC and HLF could conceivably account for a significant source of TFPI in pleural fluids. Moreover, immunohistochemical analysis of normal and diseased pleura demonstrate that expression of TFPI antigen by 
a)

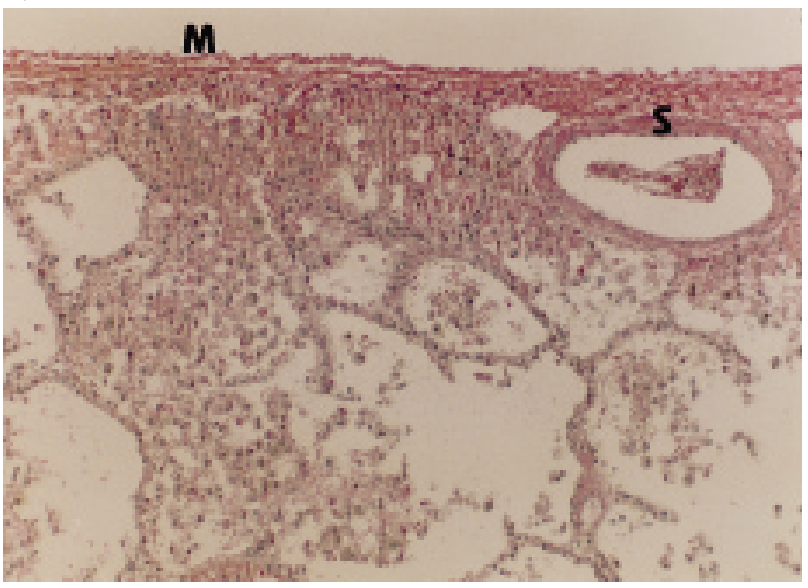

b)

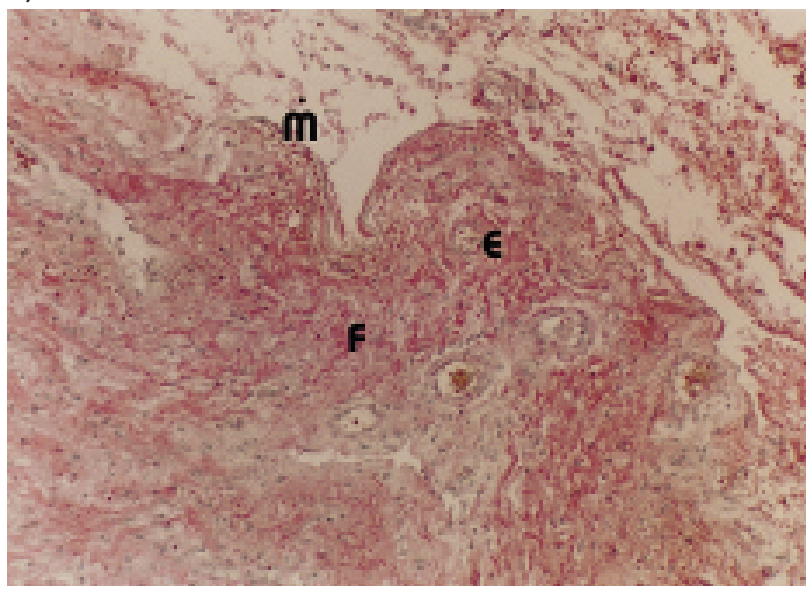

c)

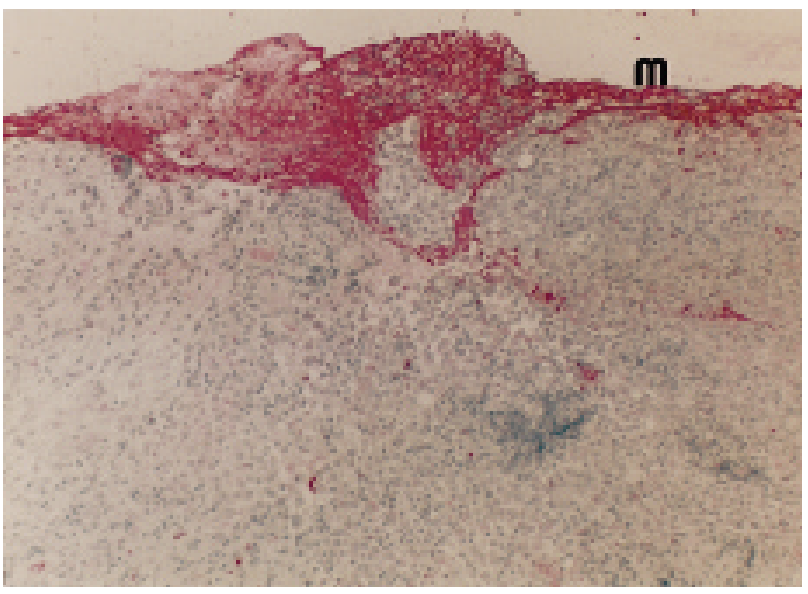

Fig. 6. - Immunohistochemical analysis for tissue factor pathway inhibitor (TFPI) antigen expression by human pleura $(\times 100)$. a) TFPI immunoreactivity at the mesothelial surface of the normal pleura. Submesothelial lung tissue is also reactive. M: mesothelium; $\mathrm{S}$ : vascular smooth muscle. b) TFPI immunoreactivity demonstrated along the mesothelial surface (M) and subpleural fibrotic bands $(\mathrm{F})$ in a case of parapneumonic effusion. TFPI immunoreactivity is also seen in the fibrinous exudate and in endothelial cells of subpleural blood vessels (E). c) TFPI immunoreactivity demonstrated in adenocarcinoma invading the visceral pleural surface. Tumour cell nests are surrounded in part by TFPI antigen identified in extracellular fibrinous material. TFPI antigen is also seen in the reactive overlying visceral pleura $(\mathrm{M})$. visceral pleura is readily detectable, further indicating that pleural mesothelial cells are a likely source of TFPI in pleural fluids. Another source of pleural fluid TFPI could be pleural macrophages as adherent monocytes/macrophages are known to express TFPI $[11,15,17]$. Therefore, exudation or leakage from the vascular compartment (either due to endothelial injury in inflammation or increased hydrostatic pressures in CHF) appears unlikely to be the sole explanation for the presence of TFPI in pleural fluids, as plasma TFPI is bound to large lipoprotein particles and therefore is less likely to exit the vascular compartment [26]. Furthermore, if exudation from leaky vasculature was the critical determinant of pleural fluid TFPI, then significantly elevated pleural fluid TFPI levels in patients with empyema/parapneumonic effusion would probably have been detected. Thus, it appears unlikely that TFPI found in pleural fluids was derived solely from exudation from vascular leakage. Resident cells (mesothelial cells and fibroblasts) in the pleural compartment appear to be a significant source of pleural fluid TFPI. These same cells and malignant mesothelioma cells are probably the major sources of TFPI that is locally elaborated in the pleural space by this tumour.

In general, the pleural cell types studied expressed TF mRNA at an early stage $(\sim 2 \mathrm{~h})$ upon stimulation with a number of pro-inflammatory stimuli likely to be present in the pleural compartment in inflammation and cancer. In contrast, the expression of TFPI mRNA by these cells either did not increase or increased slightly upon stimulation, and the induction of TFPI activity and antigen was modest. Although the exact molar ratio of TF and TFPI activity on the surface of pleural mesothelial cells and fibroblasts was not determined, it appears that, in the first several hours after induction or injury, TF expression may be prominent and precede TFPI expression, tipping the balance between procoagulant and anticoagulant activity in favour of fibrin deposition at the cell surface. Once synthesized, the anticoagulant TFPI, which is known to be primarily associated with the cell surface glycosaminoglycans $[29,30]$, is probably available at the cell surface to inhibit ongoing formation of procoagulant TF/VIIa complexes. Additionally, the TFPI secreted into the pleural fluid may be responsible for inhibiting the TF particles shed by pleural mesothelial cells [25]. Furthermore, the extracellular antigen noted in pleura invaded with adenocarcinoma may represent antigen secreted into the extracellular matrix as has been previously reported for TFPI in a preliminary study in lung fibroblasts [18] and for TFPI-2 in the endothelium [31].

The effect of serum-stimulation on TFPI mRNA expression by serum-starved fibroblasts in the current study differs from those reported previously $[18,19]$. The authors now report that primary fibroblasts from adult lung explants were serum-starved overnight followed by stimulation with $10 \%$ serum which caused a marginal ( 1.2fold) increase in TFPI mRNA expression. These cells did not tolerate longer intervals of serum starvation. In a previous study [18], human foetal lung fibroblasts were serum-starved for a significantly longer duration, i.e. 72 $\mathrm{h}$, followed by stimulation with $15 \%$ serum for $8 \mathrm{~h}$, which caused a significant (two- or three-fold) increase in TFPI mRNA expression. These differences may be attributable to the shorter duration of serum-starvation in the present 
study, which may not allow a complete reversal of the stimulatory effects of serum on TFPI mRNA expression. Accordingly, the baseline TFPI mRNA levels in serumstarved fibroblasts were substantial, making induction difficult to detect.

The significance of increased TFPI in malignant pleural effusions is not clear at this time. However, the authors infer that the presence of anticoagulant activity in the pleural space may contribute to the inhibition of local fibrin deposition (due to TF expressed by tumour cells) as do natural anticoagulants in plasma [32]. Inhibition of fibrin deposition in malignant pleural effusions may be due, in part, to TFPI, which could contribute to the paucity of loculations in this condition. In empyema, the authors infer that the levels of TFPI are insufficient to block the profibrotic influence of mediators released in a relatively high-grade pyogenic pleural injury.

In summary, the current study indicates that tissue factor pathway inhibitor is expressed in vivo in the pleural space by pleural mesothelial cells, and suggests that lung fibroblasts could also elaborate this inhibitor. However, early in inflammation, tissue factor pathway inhibitor expression in these cell types is not induced in significant amounts by selected inflammatory mediators likely to be present in the inflamed pleural space or in pleural neoplasia, whereas tissue factor procoagulant is enhanced several-fold. These concurrent changes would be expected to promote pleural fibrin deposition. Thus, it is likely that local administration of tissue factor pathway inhibitor or agents that inhibit tissue factor might be beneficial in preventing pleural fibrin deposition in such circumstances. Indeed therapeutic use of tissue factor pathway inhibitor has been found to be beneficial in animal models of several diseases with underlying pathological tissue factor-initiated clotting, such as sepsis, coronary thrombosis, microvascular anastomosis, ischaemia reperfusion injury, etc. [14]. The potential impact of such interventions in pleural inflammation and malignant mesothelioma remains unknown at this time. However, the known efficacy of anticoagulant as well as fibrinolytic strategies to block pleural loculation [33] suggest that augmentation of tissue factor pathway inhibitor might similarly attenuate loculation associated with fibrosing pleuritis.

\footnotetext{
Acknowledgements. The authors wish to thank $\mathrm{S}$. Lee for secretarial help in preparation of this manuscript.
}

\section{References}

1. Idell S, Zweib C, Kumar A, Koenig KB, Johnson AR. Pathways of fibrin turnover of human pleural mesothelial cells in vitro. Am J Respir Cell Mol Biol 1992; 7: 414426.

2. Kumar A, Koenig KB, Johnson AR, Idell S. Expression and assembly of procoagulant complexes by human pleural mesothelial cells. Thromb Haemost 1994; 71: 587-592.

3. Idell S, Pueblitz S, Emri S, et al. Regulation of fibrin deposition by malignant mesothelioma. Am J Pathol 1995; 147: 1318-1329.

4. Idell S, Zwieb C, Boggaram J, Holiday D, Johnson AR, Raghu G. Mechanisms of fibrin formation and lysis by human lung fibroblasts: influence of TGF-beta and TNAalpha. Am J Physiol 1992; 263: L487-L494.
5. Dvorak HF. Tumors: wounds that do not heal. Similarities between tumor stroma generation and wound healing. $N$ Engl J Med 1986; 315: 1650-1659.

6. Brown LF, Dvorak AM, Dvorak HF. Leaky vessels, fibrin deposition, and fibrosis: a sequence of events common to solid tumors and to many other types of diseases. Am Rev Respir Dis 1989; 140: 1104-1107.

7. Rapaport SI, Rao LVM. The tissue factor pathway: how it has become a "prima ballerina". Thromb Haemost 1995; 74: 7-17.

8. Bajaj MS, Ameri A, Bajaj SP. Tissue factor pathway inhibitor - a regulator of tissue factor induced coagulation. In: Green D, ed. Anticoagulants: Physiologic, Pathologic and Pharmacologic. Boca Raton, FL, CRC Press, 1994; pp. 41-65.

9. Broze GJ Jr. Tissue factor pathway inhibitor. Thromb Haemost 1995; 74: 90-93.

10. Bajaj MS, Kuppuswamy MN, Saito H, Spitzer SG, Bajaj SP. Cultured normal human hepatocytes do not synthesize lipoprotein-associated coagulation inhibitor: evidence that endothelium is the principal site of its synthesis. Proc Natl Acad Sci U S A 1990; 87: 8869-8873.

11. Werling RW, Zacharski LR, Kisiel W, Bajaj SP, Memoli VA, Rousseau SM. Distribution of tissue factor pathway inhibitor in normal and malignant human tissues. Thromb Haemost 1993; 69: 366-369.

12. Sandset PM, Warn-Cramer BJ, Maki SL, Rapaport SI. Immunodepletion of extrinsic pathway inhibitor sensitizes rabbits to endotoxin-induced intravascular coagulation and the generalized Schwartzman reaction. Blood 1991; 78: 1496-1502.

13. Sandset PM, Warn-Cramer BJ, Rao LVM, Maki SI, Rapaport SI. Depletion of extrinsic pathway inhibitor (EPI) sensitized rabbits to disseminated intravascular coagulation induced with tissue factor: evidence supporting a physiologic role for EPI as a natural anticoagulant. Proc Natl Acad Sci U S A 1991; 88: 708-712.

14. Bajaj MS, Bajaj SP. Tissue factor pathway inhibitor: potential therapeutic applications. Thromb Haemost 1997; 77: 471-477.

15. Østerud B, Bajaj MS, Bajaj SP. Sites of tissue factor pathway inhibitor (TFPI) and tissue factor expression under physiologic and pathologic conditions. Thromb Haemost 1995; 73: 873-875.

16. Ameri A, Kuppuswamy MN, Basu S, Bajaj SP. Expression of tissue factor pathway inhibitor by cultured endothelial cells in response to inflammatory mediators. Blood 1992; 79: 3219-3226.

17. Bajaj MS, Ameri A, Kuppuswamy MN, Bajaj SP. Expression of tissue factor pathway inhibitor (TFPI) and GATA-2 transcription factor by activated human monocytes. Blood 1993; 82: 343 (abstract).

18. Bajaj MS, Ameri A, Kuppuswamy MN, Bajaj SP. Synthesis of tissue factor pathway inhibitor by serumstimulated fibroblasts. Circulation 1996; 94: I-741.

19. Bajaj MS, Steer SA, Kuppuswamy MN, Kisiel W, Bajaj SP. Synthesis and expression of tissue factor pathway inhibitor by serum-stimulated fibroblasts, vascular smooth muscle cells and cardiac myocytes. Thromb Haemost 1999; 182: 1663-1672.

20. Pendurthi UR, Rao LVM, Williams JT, Idell S. Regulation of tissue factor pathway inhibitor expression in smooth muscle cells. Blood 1999; 94: 579-586.

21. Idell S, Pendurthi U, Pueblitz S, Koenig K, Williams T, Rao LV. Tissue factor pathway inhibitor in tetracyclineinduced pleuritis in rabbits. Thromb Haemost 1998; 79: 649-655. 
22. Light RW, Macgregor MI, Luchsinger PC, Ball WC Jr. Pleural effusions: the diagnostic separation of transudates and exudates. Ann Intern Med 1972; 77: 507-513.

23. Idell S, Girard W, Koenig KB, McLarty J, Fair DS. Abnormalities of pathways of fibrin turnover in the human pleural space. Am Rev Respir Dis 1991; 144: 187-194.

24. Chomczynski P, Sacchi N. Single-step method of RNA isolation by acid guanidinium thiocyanate-phenol-chloroform extraction. Anal Biochem 1987; 162: 156-159.

25. Giesen PLA, Rauch U, Bohrmann B, et al. Blood-borne tissue factor: another view of thrombosis. Proc Natl Acad Sci U S A 1999; 96: 2311-2315.

26. Sabharwal AK, Bajaj SP, Ameri A, et al. Tissue factor pathway inhibitor and von Willebrand factor antigen levels in adult respiratory distress syndrome and in a primate model of sepsis. Am J Respir Crit Care Med 1995; 151: 758-767.

27. Bajaj MS, Tricomi SM. Plasma levels of the three endothelial-specific proteins von Willebrand factor, tissue factor pathway inhibitor, and thrombomodulin do not predict the development of acute respiratory distress syndrome. Intensive Care Med 1999; 125: 1259-1266.

28. Novotny WF, Brown SG, Miletich JP, Rader DJ, Broze
GJ Jr. Plasma antigen levels of the lipoprotein associated coagulation inhibitor in patient samples. Blood 1991; 78: 387-393.

29. Novotny WF, Palmier M, Wun TC, Broze GJ, Miletich JP. Purification and properties of heparin-releasable lipoprotein-associated coagulation inhibitor. Blood 1991; 78: 394-400.

30. Kojima T, Katsumi A, Yamazaki $\mathrm{T}$, et al. Human ryudocan from endothelium-like cells binds basic fibroblast growth factor, midkine, and tissue factor pathway inhibitor. J Biol Chem 1996; 271: 5914-5920.

31. Iino M, Foster DC, Kisiel W. Quantification and characterization of human endothelial cell-derived tissue factor pathway inhibitor-2. Arterioscler Thromb Vasc Biol 1998; 18: 40-46.

32. Elgue G, Sanchez J, Fatah K, Olsson P, Blomback B. The effect of plasma antithrombin concentration on thrombin generation and fibrin gel structure. Thromb Res 1994; 75: 203-207.

33. Strange C, Baumann MH, Sahn SA, Idell S. Effects of intrapleural heparin or urokinase on the extent of tetracycline-induced pleural disease. Am J Respir Crit Care Med 1995; 151: 508-515. 